A R T I C L E I V.

\title{
RECENT PROGRESS IN SURGERY.
}

BY J. MASON WARREN, M.D.

or sostos.

READ AT THE ANNUAL MEETING, MAT 25, 1894.

\section{Gentlemen,-}

THE honor which you annually confer in the appointment of the orator of our yearly festival imposes no ordinary duty, in view of the eloquence and ability which have so uniformly characterized the lessons delivered from this chair.

In instituting this Annual Address, the founders of our Society seem to have intended to call in turn upon its fellows for such lessons as individual experience might suggest; and I am the more impressed with this thought, when I reflect, that, of the eminently practical and philosophical discourses which have been published under its auspices, the best and the most important have been upon subjects intimately connected with the daily studies and pursuits of their authors. In taking Surgery, therefore, as

- At an Adjourned Meeting of the Mass. Medical Society, beld Oct. 8, 1860, it was

Resolved, "That the Massachusetts Medical Bociety hereby declares that It does not consider Iteelf as having endorsed or censured the opinions in former published $\Delta$ nnual Addreases, nor will it hold itself responsible for any opinions or sentiments edranced in any future oimilar addresses."

Resolved, "That the Committee on Publication be directed to print a atatement to that eflect at the commenoement of each Annual Addreas which maj hereatier bo prabliched." 
my theme, I propose to review the experience of the past thirty years, embracing as it does a period which will be ever memorable for great practical inventions and splendid scientific discoveries.

At the very threshold of our subject, we encounter fundamental changes in the present manner of viewing and treating disease, as compared with the theories and practice which have prevailed within the memory of many even of our younger brethren. The important part borne by eminent members of our own body in working out and illustrating this great revolution, demands at least a passing notice of a few of its successive phases, as developed among us, and promulgated by the authority of our Society.

Twenty-nine years ago, a great truth, which had already dawned upon a few leading minds, first found distinct utterance in Dr. Bigelow's admirable discourse upon "Self-limited Diseases ;" the leaven of which has been silently but steadily at work, until it has completely changed the whole aspect of medical practice. In this paper, the great principle is first distinctly enunciated, that many of the most common diseases have a fixed course and duration, which cannot be abridged or materially changed by the exhibition of medicines. In such cases, therefore, the duty of the physician consists chiefly in mitigating sufferings incidental to the disease, while he prevents the officious employment of violent measures, which, from the nature of the case, can only be injurious. The lesson taught is faith in the curative powers of nature.

- Self-limited Diseases. By JACor BigrLow, M.D. Boston : 1835. 
In another address," sparkling with the characteristic genius and brilliancy of its distinguished author, which, once heard, is never forgotten, and the like of which we scarcely expect to hear from other lips, we are presented with a vivid picture of the potency of many drugs for harm; and, in view of the awful destruction of human life by these powerful agents when unskilfully administered, the conviction. is brought home to every judicious mind, that it would be a less evil even to abjure their use, than to countenance their indiscriminate employment by ignorant and unprincipled men.

Yet another paper, $\dagger$ addressed to us in the form of a paternal letter from our Nestor, whose presence we always welcome, and to whom we delight to point as a living ideal of the good and wise physician, shows us that the very drugs which are often perverted to the greatest harm are also among our most potent agents for good: like sharp tools, they are only dangerous in the hands of those who have not learned how to use them.

The last of these addresses $\ddagger$ (in point of time) is, in some sense, a summary of the whole matter. Recognizing the fact that many self-limited diseases end in recovery, we are shown, that in other diseases, equally self-limited, the natural tendency is often to the destruction or permanent injury of the affected organs; and that, in many of these very diseases,

\footnotetext{
- Currents and Counter-currents in Medical Science. By OrIver WenderL Holyes, M.D. Boston: 1860'.

+ Jackson on the Utility of Medicine. Boston: 1861.

† The Reality and Certainty of Medicine. By Morrinl Wrux, M.D. Boston: 1863.
} 
the attendant phenomena may be so far modified by rational treatment as to make all the difference between life and death to the patient. Secondly, many diseases are not self-limited; that is, they do not appear to have any definite and predetermined period of incubation, progress, and decline: and it is in this class especially, as well as in the early or formative stages of many usually included in the former class, that great and beneficial changes may be wrought, or even the disease cut short altogether by the application of the established principles of the healing art. Medicine, therefore, is a real and a beneficent art, although its most useful instruments may be capable of being perverted to mischief by charlatans and pretenders. The lesson of the last year is, the reality and certainty of the healing art. It should encourage each one of us to labor to improve himself in the knowledge of the principles of that art.

The influence of modern improved theories of pathology and therapeutics, although generally associated in the mind with the practice of medicine, has been almost equally felt in nearly every department of surgery. The intimate connection between the two sister branches of the healing art, illustrated in the last generation by Abernethy, and just enforced anew from the same chair by his most distinguished successor, renders it impossible for any improvement in the one to remain long unfelt in the other. Especially are these changes seen in the present treatment of chronic surgical diseases, and in the amelioration of the severe discipline which was formerly con- 
sidered essential to prepare a patient for an operation, or to protect him from its supposed consequences.

While these great improvements have been in progress in the general or constitutional management of surgical patients, it may seem to a casual observer, that, in local treatment, we in this neighborhood have possibly retrograded from the practice of our fathers. I remember the time, when, after an amputation, or the excision of a breast or a large tumor, it was the universal rule to bring the edges of the cut integuments together nicely with straps, compresses, and a bandage, with the full assurance of finding the wound neariy healed on the removal of the dressings. At the present day, however, such a result is seldom attained in city practice; union by first intention being, for the past twenty years, the rare exception. Occasionally, the margins of the skin seem at first to unite, and promise a speedy cure; but suppuration almost always ensues in the deeper parts, and it soon becomes necessary to give vent to the secretions, either by breaking up the newly-formed adhesions, or by making a new opening.

The causes of the change which has taken place here in the processes of repair are found in the impaired hygienic condition of our city, arising out of the great increase, and consequent crowding, of its population; for it is only necessary to travel a few miles into the country to find again the same favorable influences which we formerly enjoyed. This explains, also, what must have struck every one as an anomaly in Parisian surgery: I allude to the fashion, which, until within the past few years, almost exclu- 
sively prevailed there, of taking effectual measures to prevent union by first intention. The obvious explanation of this practice is, that, in the hospitals of a crowded city like Paris, immediate union of the deeper tissues is of the rarest possible occurrence. The early union of the integuments, therefore, if it occur, can only aggravate the trouble by impeding the escape of the sloughs and débris from the granulating surfaces beneath; but it cannot be denied, on the other hand, that the means taken to prevent the confinement of the discharges often produced so much irritation as greatly to increase the extent of the destructive action.

At the period when I was prosecuting my studies in Paris, M. Roux was almost the only surgeon of note in that city to break in upon this routine of irritating dressings. He had visited England, and had there seen the good effects of the simpler treatment adopted in the London hospitals, upon which he had written a valuable treatise. But the classical doctrines of the French school were not to be subverted in a day; and it is only within the past few years that a new generation of surgeons, working in the midst of more favorable hygienic influences, have been able to raise Parisian practice, in this respect, to the English and American standard.

The possibility of obtaining union by first intention lies at the foundation of the art of plastic surgery ; and it is in a great measure owing to the general introduction of modes of treatment favorable to this result that the department of operative surgery has of late made such remarkable progress. 
But another even more conspicuous change presents itself when we contrast the operative surgery of to-day with that familiar to all but the very youngest among us. I refer to the present universal employment of artificial ancesthesia; and it is with especial pride that we reflect that it was in our own city, and under the auspices of members of our own body, that the full value of this immortal discovery was first demonstrated and published: and it is truly remarkable, that, at the present day, artificial anæsthesia is best attained by ether, used in substantially the same manner as when it was first tried in surgical operations at the Massachusetts General Hospital. While chloroform has killed its hundreds, and while hardly a journal arrives from Europe without some notice of new cases of death from the use of this potent agent, wonderful to relate, out of the hundreds of thousands of cases of etherization, the first victim to its action is yet to be recorded. It is not pretended by this statement entirely to abjure the use of chloroform, which, in some exceptional cases, is certainly preferable to any known anæsthetic agent; being far more concentrated in form, more agreeable, and more active in administration, than any of the many substitutes which have been proposed for it. On the battle-field, especially, its greater portability is likely always to secure the preference for it over safer but more bulky anæsthetics.

The first, and perhaps the most important, application of ether is in producing unconsciousness of pain; and it is for this boon that the patient will ever be chiefly thankful. To the surgeon, also, the 
non-infliction of pain is often a matter of the greatest moment; for he can now undertake at his ease a long and tedious dissection, or a delicate exploration of an acutely inflamed cavity, undisturbed by involuntary movements of his victim. The power to abolish pain has also materially enlarged the domain of operative surgery, not only by diminishing the dread of common operations, and allowing of their more frequent performance, but also by admitting into the list of justifiable operations some whose severity would otherwise, in most cases, forbid even the thought of attempting them.

The other great application of ether in surgery depends upon its power of relaxing the voluntary muscles by inducing a state of the brain analogous to coma. In the deep sleep of complete etherization, the manipulation and reduction of fractures and dislocations, the diagnosis and treatment of anchyloses, the reduction of strangulated hernia, \&c., are immensely facilitated. The question of its use in certain special departments of surgery will be noticed elsewhere.

This is not the place to dwell on the very important uses of ether in midwifery, and in painful or convulsive medical diseases; but of its inestimable value in the alleviation of suffering during the last moments of life, and letting the patient gently downwards in his passage to the other world, I cannot omit this passing notice.

T'he duty still remains for the public to show their appreciation of the value of this grand discovery by awarding to the several gentlemen who were instru- 
mental in its introduction a substantial testimonial, which shall be in some degree commensurate with the benefits which they have conferred upon society.

The ancsthetic action of cold, developed by a refrigerating mixture of ice and salt, as suggested by the distinguished Dr. Arnott, may be advantageously substituted for etherization in many cases of slight operations confined to the skin and subcutaneous tissues. The operation must be performed quickly, as the parts thaw with great rapidity as soon as the warm blood begins to flow from the divided vessels. For operations requiring nice dissection the method is inapplicable, owing to the rigidity of the frozen parts.

OPERATIONS FOR STONE IN THE BLADDER.

The great surgical novelty, at the time of my first visit to Europe, was the now-familiar operation of lithotrity. The possibility of breaking up the stone in the bladder, and extracting the fragments through the natural passages, had been shortly before demonstrated by Civiale, and rendered safe, expeditious, and practically useful, by the improved instrument of Heurteloup. It was my good fortune to become acquainted with Baron Heurteloup in London through the courtesy of Sir Astley Cooper, and to witness some of the first operations performed by the new method in that city. It will be remembered, that he seized the stone precisely as is done with the modern lithotrite; and then, fixing the instrument firmly to the table in a vice, crushed it by repeated blows of a hammer. At this time, two important defects in 
the operation threatened to prevent its general adoption. These were, 1st, The great inconvenience of frequently adjusting the instrument in the vice, which was soon overcome by the substitution of a screw or rachet movement for the hammer; and, 2dly, The danger of fragments of the stone so clogging the jaws of the lithotrite as to render its withdrawal extremely difficult, and in some cases impossible except by severe laceration of the urethra. This defect, also, was soon remedied, by making an opening, or "fenestrum," in one of the jaws, through which the fragments readily escape.

The skill attained by $\mathrm{M}$. Civiale in this very delicate operation was almost miraculous. The instrument was slowly introduced through an irritable urethra into an inflamed bladder,-the mind of the patient being at the same time assured by gentle management,-the stone caught and broken, then recaught and broken again, all seemingly without effort, and without evoking any sign of pain. I have attended a great number of operations by $\mathbf{M}$. Civiale,-many in public, and some in private practice. He carried with him a single stone-crusher, a catheter, and a small syringe. Entering the room of the patient, he would pass the catheter, inject three or four ounces of water, introduce the lithotrite, and seize and crush the stone, all in the time ordinarily occupied by a short medical visit.

The success of lithotrity, so far as my own observation goes, depends upon the following circumstances : 1st, To use an instrument of moderate size, and so constructed as thoroughly to clear itself of 
the fragments. 2dly, To inject the bladder moderately with water. $3 \mathrm{dly}$, Not to move the instrument about too freely. The importance of this last precaution cannot be too strongly enforced. If the instrument is rudely scraped over the sensitive mucous membrane, already irritated by contact with the rough stone; or if the jaws are frequently opened and shut without any well-defined method; or if the stone is carelessly seized, entangling with it perhaps a part of the walls of the organ,-inflammation, or even gangrene and death, may ensue. By at once gently sinking the beak of the instrument, however, into the most dependent part of the bladder, opening and giving it a slight oscillating movement, the stone will, in almost every instance, fall readily into its grasp, and may then be raised into the middle of the cavity, and there broken. The same process may be repeated upon one or tivo of the larger fragments; taking care, however, not to protract the operation beyond a few minutes. A large catheter may now be introduced, and some of the finer particles allowed to escape through it. It is not, however, until after the lapse of two or three days, that the bladder recovers sufficient tone to expel the fragments spontaneously.

In old persons, in whom the prostate is more or less enlarged, the stone is often concealed in a cavity behind it, and requires that the beak of the instrument should be turned backwards, and the stone pushed out from its lodging-place before it can be properly seized.

Ether is a most valuable adjuvant in a great pro- 
portion of cases of lithotrity. When I first urged its employment in this operation, in a paper published in "The American Journal of the Medical Sciences" in 1848, many surgeons objected (and some still object) to its use, upon the ground that the consciousness of the patient is necessary to give warning if the folds of the bladder become entangled in the jaws of the instrument. In answer to this objection, it may be stated, that the mere contact of the instrument, in an irritated state of the organ, will give ${ }^{*}$ rise to greater suffering than the actual engagement of the mucous membrane in other cases; and that, to a surgeon at all in the habit of performing this operation, the interposition of a fold of soft tissue is at once perceptible, although $I$ have never known the patient to exhibit any unusual pain from this circumstance. In cases of extreme irritability of the bladder in persons in an advanced stage of the disease, where there is an entire want of power to retain the urine, the bladder embracing the stone, and the urine passing off almost as soon as secreted, I have been astonished at the vast quantity of ether which is required to effect perfect relaxation, so as to admit of the injection of the small amount of water necessary to prepare it for the subsequent manipulations.

The subject of lithotomy at once brings to mind the memory of Dupuytren, the great lithotomist of his time, whom I saw in the zenith of his fame, while engaged in the delivery of those remarkable courses of lectures which were soon after collected, and published under the title of "Legons Orales de 
Clinique Chirurgicale." He was by far the best lecturer of his day; delivering his ideas with wonderful clearness and always discussing questions of the greatest practical importance. In the present department of surgery, we owe to him the improved method known as the "bilateral," which, with slight modifications, is still a favorite operation with many - French and American surgeons, and which I have myself performed with great satisfaction. Its chief peculiarity consists, as is well known, in the transverse incision of the skin, which is made directly in front of the anus ; and, secondly, in the double division of the prostate by the "lithotome caché. The absence of important nerves and vessels in the median raphé affords a strong argument in favor of a median over the common lateral incision; and the recent revival of perineal section by Mr. Syme has demonstrated the fact, that the bladder may be safely and easily reached in this manner. Influenced by these considerations, I have several times operated by a median incision in the raphé, dividing the prostate with the double lithotome or with a bistoury. The advantage of this method over the transverse incision of Dupuytren is the greater room which it affords for the withdrawal of the stone through the external wound; while all its peculiar advantages are secured by the double incision of the prostate. It appears that a similar operation has been also performed with success by Henry Thompson, of London, who attributes its invention to M. Civiale.

Of other eminent lithotomists whom I saw, and with whom $I$ had the honor of a personal acquaint- 
ance, Mr. Key of London, and Mr. Liston of Edinburgh, were especially distinguished. The former of these gentlemen operated in a manner peculiarly his own ; using an almost straight staff, and making all the incisions with a single round-pointed knife. Mr. Liston performed the ordinary lateral operation, in which his dexterity was proverbial.

Lithotomy, notwithstanding the extraordinary success said to have been attained in certain sections of our own country, is nevertheless, in town and hospital practice, an operation attended with considerable risk. It is especially indicated in young children, in whom the urethra is too narrow to admit of the safe introduction of the crushing instrument; and in the case of encysted calculus, which cannot be reached in any other way.

The operations for stone, in this neighborhood, may be said to be very rare. Dr. J. C. Warren, in a paper published in $1 \varepsilon 44$, stated, that, in the course of forty years, he had been called on to perform all the operations for stone which had been done in Boston. The whole number had not exceeded twenty-five cases, and the population had increased during this time from twenty-six thousand to upwards of a hundred thousand. Of the twenty-five cases, not more than three were in persons natives of Boston or vicinity. In the last thirty years, I have myself operated on rather more than thirty cases; and the operation has also been performed by other surgeons. Most of these cases were from a distance, and but four or five of them belonged to Boston. Two-thirds of these cases were operated on by lithotrity; and, 
as well as those by lithotomy, have proved successful.

\section{FRACTURES.}

The great importance of these injuries, and the absolute necessity in most cases of proper surgical treatment, have given them a most prominent place in the surgery of all ages. From the earliest times of which we have any record, down to the present day, the treatment of these injuries has been oscillating between the employment, on the one hand, of powerful engines for their reduction, and retention in place; and, on the other hand, of simple rest in an easy position. Both of these extreme modes of practice have been extensively employed within the past thirty years, and both methods have undergone many and great improvements. I have myself become more and more convinced of the propriety of doing as little as possible for the first few days ; and have generally been content with making a slight extension, so as to bring the broken ends of the bone together, so far as they will come naturally, and without violence; then waiting until the irritability of the muscles has subsided before proceeding to the application of the permanent apparatus of splints and bandages. In very many fractures, where great immediate distortion is produced by muscular contraction, after a few days of rest, combined perhaps with gentle extension, the broken bones seem quietly to settle down into their proper places, and the whole treatment resolves itself into careful watching, with occasional slight manipulation, to remedy accidental 
displacements and to prevent excoriation. Many years ago, in a conversation with Dr. Dugas, an eminent surgeon of Georgia, I was much struck by the answer which he made to my question, how he treated fractures of the thigh. "I tie a brick to the foot," said he, "and let it hang over the end of the bed." The weight of the brick, on the one hand, and the voluntary efforts of the patient to resist the traction which tends to drag him down, on the other, constitute a very simple and efficient means of extension. I repeated the experiment-which is, at least, as old as the time of Hildanus-upon a powerful man with a fracture of the thigh. The extension was easily and effectually maintained during the three or four weeks that the man remained under my care; and the case progressed with less irritation than common. This mode of extension was also employed in France by Seutin, and has been still more recently revived in New York by Drs. Buck and Swinburne. I have lately treated several fractures in this way at the Massachusetts General Hospital, as have other surgeons of that institution, and with excellent results. Fqr fracture of the neck of the thigh-bone, it is one of the best methods in use. Counter-extension, by a perineal strap, may often be employed with advantage; or a similar end may be attained by raising the foot of the bed a few inches by bricks or pieces of plank placed under the legs. The great advantage of this treatment consists in its leaving the limb open to constant inspection, and keeping the injured parts free from all irritating pressure from splints and bandages. Eversion is 
prevented by placing bags, filled with sand, by the side of the limb. In very old and feeble patients, who frequently cannot bear even this slight restraint, the double-inclined plane or fracture-bed is to be preferred to any other apparatus.

Transverse fracture of the patella, attended, as it often is, by great separation of the fragments, may be most successfully treated by position alone. This I tried at first with the body slightly bent, and the limb raised at a large angle from the bed. The effect, however, of this constrained position, was that the patient constantly endeavored to escape from it: I was therefore led to place the limb perfectly flat on the bed, which I found to answer better than the theoretical posture, devised with the idea of more perfect muscular relaxation. The old methods for confining the upper fragment by bandages are always inefficient unless aided by a correct position of the limb, and are useless with it. They give rise to great swelling and much needless suffering, besides actually deranging the fragments by so tilting them as to prevent their proper approximation.* By the use of the ingenious steel hooks of Malgaigne, it is claimed that a still more accurate adjustment of the parts may be secured; but the plan has found little favor in this country.

The excellent results which we now obtain in the treatment of fracture of the thigh by extension, are due in a very great degree to the introduction, by

- The effect of bandages, in tilting the fragments, is well shown by specimens in the raluable cabinet of the Boston Society for Medical Improvement, under the care of Prof. J. B. S. Jackson. 
Dr. Crosby, of Manchester, N. H., of extending straps of common adhesive plaster, as a substitute for the painful and inconvenient methods with bandages, or the gaiter or handkerchief.

Fracture of the clavicle is perhaps one of the commonest of the injuries to bones, and is one of the most troublesome to treat with the old complicated apparatus. When students, we were taught to apply Desault's bandage, which consists of eighteen yards of roller, confining the arm in every conceivable way, and frequently torturing the patient in addition by firm pressure upon one or the other of the fragments at the seat of the injury. Many years ago, I brought Dr. Fox's simple apparatus from Philadelphia; and it was immediately introduced into the hospital, where it has been used ever since with some slight modifications. It consists, essentially, of a pad for the axilla, and a bag for the arm slung from the opposite shoulder. Many cases of this fracture do well without especial treatment; and we often see it already in a fair way of recovery in children brought to us for supposed lameness of the shoulder resulting from a fall a week or two before. In bad cases, where there has been much injury and swelling of the soft parts, or where one of the fragments has been driven down by the blow, so as scarcely to be detected by the most careful examination, on confining the patient to his back in bed, I have often seen the broken end rise up, as it were, and finally assume nearly as good a position as in the case of a simpler injury treated by the most complicated apparatus. With the exception of some 
occasional deformity, the results of fracture of the clavicle are almost always favorable. In the very large number of cases which have come under my notice, I have never known union to fail except in one instance,-that of a sailor severely injured at sea by a fall from the mast, and not subjected to treatment; the blow, in this case, being a direct one, at the seat of fracture.

Fracture of the lower third or small part of the leg is often very vexatious to manage, owing to a projection of the tibia, which often takes place, and is attended with more or less deviation of the leg from a straight line; thus giving rise occasionally to lameness by restricting the range of flexion of the anklejoint. 'This accident is best avoided by treating the leg upon a double-inclined plane, applying extension and counter-extension by means of adhesive straps fastened above to upright stanchions connected with the leg part of the apparatus, and below to the foot-piece, - an arrangement suggested by Dr. S. D. Townsend. This fracture may also be successfully treated, in some cases, with the starched or plaster bandage. A slight degree of deformity almost always follows this injury, where there has been any displacement in the beginning.

For fracture of the fibula near the ankle, with displacement of the lower fragment, the powerful sidesplint of Dupuytren fulfils every indication.

Fracture of one of the condyles of the humerus into the elbow-joint is very apt to be followed by adhesions, and loss of motion, even under the best management. If there is no displacement of the fragment, 
it is best to dispense altogether with splints, merely supporting the arm in a sling. Where splints are necessary, they should be removed at the end of ten days or a fortnight, and passive motion commenced as soon as the tendency to displacement is overcome.

Fracture of the lower end of the radius, which is of so frequent occurrence in winter from a fall on the hand, is very apt to be followed by deformity and great impairment of the functions of the part. I have of late treated this fracture almost exclusively with the simple and ingenious splint invented by Dr. Henry Bond, of Philadelphia, and described in the American Journal of the Medical Sciences for April, 1852. For facility of application and of subsequent inspection, as well as for comfort to the patient, this apparatus appears to me to offer important advantages over any hitherto invented,- - not excepting the famous pistol-shaped splint of Nelaton.

Of modern appliances for the treatment of fractures, the starched bandage of Seutin, or, still better, the dextrine bandage of Velpeau, or the plaster of Paris apparatus, is one of the most important. There are, in fact, but few cases of fracture in which this apparatus is not useful at some stage of the treatment. In simple fractures, where there is not much injury of the soft parts, it may often be applied with advantage immediately upon the receipt of the injury. In other cases, it is necessary to wait until the swelling and inflammation have subsided. After union has been effected by the use of other appliances, the starched or dextrine bandage is very useful in sup- 
porting the newly-formed callus, and guarding the limb against accidents when the patient leares his bed.

The application of these bandages is very simple. A common roller is to be passed through the adhesive liquid, either starch paste, or solution of dextrine, and is then to be applied to the limb in the ordinary manner, taking care to make as few reverses as possible. A dry roller of old linen or cotton should be first applied, to prevent adhesion of the bandage to the skin. The dextrine solution, which may be made in part with alcohol, dries sooner than the starch, and makes a firmer case with the same thickness of roller. If starch is used, the whole should be strengthened by strips of wet pasteboard, placed on the outside of the dry roller before applying the starched one.

The plaster apparatus consists, first, of a soft roller or a thin layer of cotton, applied next to the skin, and covered by a second roller, wet with water. The whole bandage is then covered with plaster mixed with water to the consistency of cream, and confined, if necessary, by another roller. The surface of this may be smoothed with a little more plaster, applied with the palm of the hand, and the whole apparatus completed by a coat of shellac varnish. This apparatus is easily applied, and becomes perfectly solid in the course of the short time required for its application. The plaster should not be wet until the moment it is to be used; and, if it still sets too quickly, a little alum water may be added.

The starched bandage may be employed with 
great benefit in those very vexatious and often un- . manageable injuries, - sprains of the ankle; thus allowing, in some cases, of locomotion at once, where a very tedious confinement would be necessary under other treatment. I have also employed it with excellent results in that very troublesome disease, milk abscess; also in swelled testicle, in which its success is superior even to strapping with adhesive plaster.

In oblique fractures of the femur,-except, perhaps, in very young children,-more or less shortening always remains, even under the most skilful treatment. Cases are often shown of limbs in which it is claimed that shortening has been wholly prevented; but, on careful measurement, I have never failed to detect it. It is, however, generally so slight as to be of little consequence,-frequently not exceeding a quarter to a half inch ; in which case it is completely compensated by a deviation of the pelvis.

The time required for the union of a fracture of the thigh is generally stated at six weeks; but it by no means follows, that, after this interval, the callus has become sufficiently consolidated to admit of any use of the limb in standing or walking. In fact, the too early use of a fractured limb is often followed by a gradual bending of the newly-formed bone ; resulting, sometimes, in considerable distortion. If, for any reason, it is thought proper to allow the patient to rise from his bed at this stage of the cure, the limb should always be supported by splints; or, better, by a starched or plaster bandage.

Angular distortion, after fractures, should be treat- 
- ed, as soon as discovered, by gradually increased pressure, applied by means of a straight splint and a roller or adhesive straps. It is worthy of remark; that very great deformity may be corrected in this way, in young persons, even long after the receipt of the injury.

A single word may be said upon fractures of the skull with depression. The present rule in surgery is, in case of simple depression of the skull, uncomplicated by a wound of the integuments, and without cerebral symptoms, not to interfere with the fracture; and the same rule has been applied to many cases of compound fracture, where, for the moment, the brain appears not to be affected. Serious accidents may occur in these patients at a period more or less remote from that of the injury. Some are affected with chronic headache; and many, after the lapse of a year, or much later, suffer from epileptic convulsions, which render their lives miserable. The great mortality of operations on the skull, performed to elevate depressed bone after accidents, has led, perhaps, to the extreme of conservative practice, which may possibly be modified by future experience.

\section{DISLOCATIONS.}

In following the wards of Lisfranc, in Paris, I was struck by a number of cases of injuries of the shoulder-joint, which he considered anomalous, and which were supposed to be partial dislocations of the shoulder. These patients had all received their injuries by a blow upon the joint itself: the head of 
the humerus seemed to be displaced slightly forward, or as if on the edge of the glenoid cavity. The head could be easily replaced by a slight effort, but at once resumed its former position when abandoned to itself.

Some time afterwards, I observed, in the "MedicoChirurgical Review," a drawing of a case which had been considered one of partial dislocation, but in which it was shown that the front part of the socket had been broken off; thus allowing a slight displacement of the head of the humerus forward, and ending in the formation of a new socket a little in front of the old one.

About this time, a sailor was brought into the Massachusetts General Hospital, who had fallen from the mast of a ship, and had received fatal injuries. Among others, there was apparently a partial dislocation of the shoulder. On examination, a distinct ecchymosis was found on the external aspect of the joint; and the front part of the socket had been broken off, so that the head of the humerus lay partially below the coracoid process.

During several years in practice, before I fully understood the nature of the accident, I was much struck by observing cases of dislocation of the shoulder, in which, after reduction by the usual methods, the bone showed a remarkable tendency to return to its original state of displacement. In all these cases, I found, on a strict examination of the patient, that the injury had been inflicted by a blow upon the joint itself. Latterly, I have constantly met with cases of recent dislocation which have been brought into the 
hospital on account of the supposed failure to effect reduction, but in which the real difficulty lay, not in replacing the bone in its socket (which was very easily effected), but in retaining it there after the removal of the artificial supports. All these cases are, in fact, fractures of the edge of the socket, caused by a blow received on the shoulder; and I am almost prepared to say, that a simple dislocation of the shoulder, and I may also say of the hip-joint, never occurs from a direct blow on the part. I certainly have never seen it myself, nor have I seen it satisfactorily described by others.

This fact is one of considerable practical importance. When a patient comes under our notice with a dislocation of the shoulder-joint, he may be asked in what manner the injury was received. If by a blow on the shoulder, a bruised spot will generally be found; and if an ecchymosis also appears within a short time, either in front of the joint or along the side of the arm, the diagnosis of fracture of the socket may almost certainly be made. If, on the other hand, the patient has received the blow on the hand or elbow, with the limb, at the same time, more or less extended from the thorax, we may expect to find a simple dislocation; or, if there has been great violence, we may possibly find it complicated with fracture of the neck of the humerus. Impacted fracture of the head of the humerus, occurring from a blow on the shoulder, is the only injury likely to be mistaken for the so-called partial dislocation just noticed.

The most important part of the treatment of dis- 
location of the shoulder with fracture of the socket consists in retaining the parts in position after they have been reduced. This object is well attained by the use of Fox's apparatus for fractured clavicle; the wedge-shaped pad in the axilla preventing the reproduction of the dislocation. In old cases, with complete displacement, considerable force is often required to break up adhesions, which are generally more tenacious than in cases of simple dislocation; probably on account of the additional inflammatory action consequent upon the fracture of the socket. Greater care and a longer persistence in the use of mechanical means are also necessary to retain the head of the bone in its place while the new socket is in process of formation. In fact, I have seen the head of the bone displaced by a slight pressure with the thumb while being examined after reduction, the arm being at the time firmly bandaged to the body,an occurrence which would be hardly possible in a simple dislocation.

I have had to treat several cases of dislocation of the shoulder, with fracture of the neck of the humerus. In two instances in which I was called while the muscles were still relaxed, and before the patient had recovered from the depressing influence of the shock, it was found possible to effect reduction by making extension of the shaft of the bone, at the same time working the separated head into its socket by firm pressure with the thumbs. In case reduction cannot be thus effected, it is still a question, whether the shaft of the bone should be carried 
back into the old socket, so as thus to make at once the best practicable joint; or whether it should be placed in apposition with the head, and an attempt made at reduction after such a lapse of time as may be thought sufficient for the union of the fragments to take place. The latter method was tried with success, by Dr. John C. Warren, on a young man, whose case he reported in the "Boston Medical and Surgical Journal" for 1828. Immediate reduction having been attempted in vain, fracture-apparatus was applied. After seven weeks, extension was made with pulleys, and the dislocation reduced. This case is reported by Malgaigne, who considers the precedent worthy to be followed in similar cases. I also attempted the same treatment in a case which occurred nearly twenty years ago; but, in the attempt to break up the adhesions which had formed during the six or eight weeks that had elapsed, the callus gave way, and the fracture was reproduced. The broken end of the bone was then placed in the glenoid cavity, and the patient recovered with a very useful arm. In another case which has lately come under my notice, the arm had been paralyzed by fruitless attempts at reduction. I saw the patient, in consultation with other surgeons, at the end of seven weeks; when it was decided to leave the broken end of the bone in the socket. I afterwards learned that the paralysis was gradually passing off, and that the patient is now recovering the use of his arm. 
Dislocation of the hip-joint, so far as my own observation goes, may take place upon almost any part of the pelvis. During an attempt at reduction, made under ether, I have seen almost every kind of displacement imitated. In the course of my practice, I have seen three cases of dislocations downwards and backwards; one of them in a boy of six years of age, which is the youngest patient in whom I have ever seen dislocation of the head of the femur. I have met with a dislocation of one thigh into the foramen ovale, the other thigh being dislocated upwards at the same time, with incomplete fracture of the neck of the bone ; the fractured portions separating, just as the head had been restored to its place in the socket.

I have only once seen a dislocation of the hip in the female, - a patient who came into the hospital during the past year, under Dr. Cabot, who reduced it ; and I believe that there is but one such instance recorded in the work of Sir Astley Cooper on this subject. The rarity of this dislocation in women is a fact of great importance in distinguishing between fractures, and displacements of the head of the thighbone.

It is well known as one of the diagnostic marks of fracture of the neck of the femur, that the foot is turned outwards, and the limb shortened. In dislocation on the dorsum ilii, the limb is turned inwards, with a like shortening. In opposition to this, I would mention the fact of having seen a fracture of the neck of the thigh-bone in an old lady over a hundred years of age, and have now the specimen in 
my possession, in which the toes were turned inwards, the fragments having become partially interlocked in that position. I have also observed, in the course of the reduction of a dislocation on the dorsum, the toes become everted; the head of the bone taking a position in front, so as to present most of the appearances usually given by a fracture of the neck of the bone.

The use of ether has made a very great change in the practice pursued in the treatment of dislocations of the hip, which can now be very frequently reduced by manual assistance only; thus enabling us in many cases to dispense entirely with pulleys, and, by successive movements of flexion, abduction, and rotation, to restore the head of the bone to its socket with a facility truly astonishing. The rationale of this mode of reduction has been lately very satisfactorily explained before this Society by the Professor of Surgery in Harvard University, who has shown, by specimens and dissections, the very important part borne by the great ilio-femoral ligament in the mechanism of the various dislocations of this joint.

I will mention a case of dislocation with supposed fracture of the acetabulum, which is interesting from its important bearing on the question of the dislocation recurring from a very moderate movement of the bone afterwards. It occurred in a powerful man, who was run over by his own cart, the hip being dislocated by the knee coming forcibly in contact with the bottom of the cart, while the pelvis rested on the ground; the limb, of course, at the time of the accident, being at a right angle with the body. 
He was brought to the hospital, and an upward dislocation detected, which was reduced after the usual manipulation, and extension by means of pulleys. On lifting the limb a few inches from the table, the head of the bone again flew out from its socket, and was reduced with even more difficulty than at first. I requested my-colleague, Dr. Townsend, to verify this fact. The patient was desirous of leaving the hospital, which I strongly advised him not to do. The limb was confined, and treated with great care; but, at the end of about four weeks, he arose from his bed without permission, and stood on the injured limb, at the same time twisting his body upon it, forcing the bone again out of its socket, and causing considerable suffering. Much cartilaginous crepitus was heard while the limb was being restored to its place. . The accident recurred a third time, from his flexing the limb too strongly in bed. He now had a starched bandage firmly applied both to the hip and to the lower extremity;-and, after a confinement of several months, he recovered. In this instance, if the patient had returned home, and the dislocation had recurred during any extraordinary movements, made, perhaps, during sleep, it might easily have been urged against the surgeon, that the dislocation had never been reduced.

\section{AMPUTATIONS.}

The question of points of election for the performance of amputation has been re-opened within the past few years, and the rule of practice materially changed from that even now taught in some of the 
approved European text-books. The old rule of amputating the leg within a few inches of the knee, for an injury, perhaps, of the ankle, has given place, in this country at least, to the much safer and in every respect better practice of saving as much of the limb as possible. This reform is due almost wholly to the invention of the improved conical socket, now so universally employed in modern artificial limbs, in which the weight of the body is sustained by the accurate adjustment of the tapering sides of the stump to the corresponding cavity made to receive it, while the sensitive cicatrix is effectually relieved from pressure.

The advantages of immediate amputation are perhaps now more fully recognized than ever before. Even during the period of depression or shock, where it would formerly have been thought necessary to wait for re-action, we now feel justified, in most cases, in proceeding at once to the operation; having learned by experience that the inhalation of ether is generally attended by a greater and more rapid restoration of the vital forces than that which follows the exhibition of alcoholic stimulants. By operating at this time, many a patient may be saved, who would otherwise die from the gradual loss of blood, and from the nervous irritation dependent upon extensive injury.

The kinds of operation which have generally been preferred in this vicinity are the circular for limbs with a single bone, and the flap for the fore-arm and leg: The introduction of the operations of Messrs. Syme and Pirogoff, for saving as much as possible 
of the lower extremity, and as substitutes for amputation in the leg, are well worthy of adoption in suitable cases.

Amputations and excisions are now being fully tested in all their varieties in the great field afforded by the present war. One amputation-that at the hip-joint-may be particularly mentioned, on account of its striking want of success. Out of twenty-three operations mentioned by Macleod as having been performed in the Crimea, all proved fatal; and thus far, during the present war, I have not heard of a single successful case. It has been thought safer, therefore, to leave a man, with a compound comminuted fracture high up in the thigh, to the chances afforded by nature, rather than to perform the amputation now under consideration.

I have had an opportunity of twice performing this amputation in Boston. One case was in a child whose limb was partially torn off by a railroad accident; the other was for a large tumor of the femur, which reached high up into the groin. The first patient died at the end of a fortnight, without evident cause, when apparently in a fair way of recovery: the other recovered. The method adopted in the last case was by making anterior and posterior flaps of integument; tying the femoral artery before making the section of the muscles.

It may be interesting to refer to the mortality, after large amputations, as shown in the statistics of the Massachusetts General Hospital during forty years; comparing them with some lately collected abroad. 
IIST OF MAJOR AMPUTATIONS PERFORMED AT THE MASSACHU. SETTS GENERAL HOSPITAL FROM 1822 TO 1850.

First.-Cases from 1822 to 1850 (reported by Prof. Gzo. Hayward).

Thigh, . . . . 88 recovered, 69 died, 19 . . Per cent of deaths, 21.6

Leg, . . . . . 60 " 50 " 10 . . “ " " " 16.6

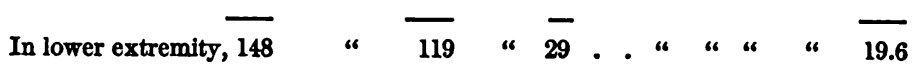

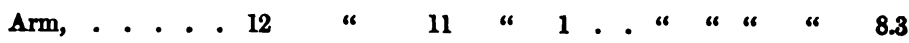

Fore-arm . . . . 13 " 11 " 2 . . “ " " “ 15.4

In upper extremity, 25 " $\overline{22}$ “ $\overline{3}$. . “ " “ "

Total from 1822 to 1850,173 ; recovered, 141 ; died, 32 : per cent of deaths, 18.5 .

Second.-Cases from 1850 to 1860 (collected by Dr. Bews. S. SHAw).

Thigh, . . . . 86 recovered, 67 died, 19 . . Per cent of deaths, 22.1

Leg, . . . . . 84 " 60 " 24 . . " " " " 28.6

In lower extremity, $\overline{170}$ " $\overline{127}$ “ $\overline{43}$. . " “ " “ $\overline{25.3}$

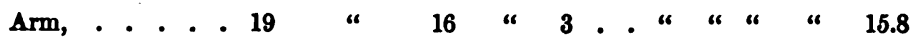

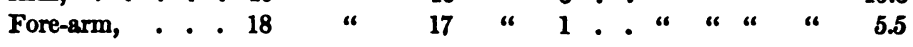

In upper extremity, 37 " $\overline{33}$ “ $\overline{4}$. . " “ “ “

Total from 1850 to 1860,207 ; recovered, 160 ; died, 47 : per cent of deaths, 22.7.

Total of Cases from 1822 to 1860.

Thigh, . . . . 174 recovered, 136 died, 38 . . Per cent of deaths, 22.8

Leg, . . . . . 144 " 110 " 34 . . " “ " “ 23.6

In lower extremity, $\overline{318}$ " $\overline{246}$ " $\overline{72}$. . " “ " " $\overline{22.6}$

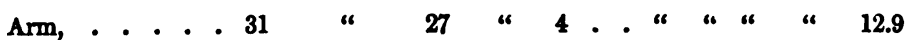

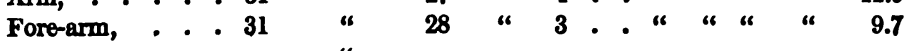

In upper extremity, 62 “

Total of amputations (except of hip and shoulder), 380 ; recovered, 301 ; died, 79 : per cent of deaths, 20.8 .

Amputations at Hip and Shoulder Joints from 1850 to 1860.

Hip, . . 2 recovered, 1 died, 1 . . . . . Per cent of deaths, 50.0 Shoulder, 16 " 10 " 6 ....... “ " " $" 37.5$

In a paper published by Mr. Callender, the mortality, after all amputations, at St. Bartholomew's Hospital, London, is given as follows :-

Total, 358; recovered, 284; died, 74 . . . Per cent of deaths, 20.7 
Dr. Norris, in the "American Journal of Medical Sciences," July, 1854, gives the following statistics of amputation at the Pennsylvania Hospital, before 1850 :

Total, 196; recovered, 148; died, 48 . . . . Per cent of deaths, 24.5.

Dr. Simpson, in his lecture published in the "Medical Times and Gazette," Feb. 6, 1864, quotes the following :-

Out of five hundred and twelve amputations of the thigh, leg, arm, and forearm, performed in the Parisian hospitals from 1836 to 1841, and collected by M. Malgaigne, two hundred and eighty-one proved fatal. In other words, fifyfive out of every hundred thus operated upon died.-Archives Generales de Medecine, tome 58, p. 389.

Out of two thousand and forty-six similar amputations occurring in British hospitals and in private practice, collected by Dr. Fenwick, five hundred and twenty-four proved fatal. In other words, nearly twenty-six in every hundred thus operated upon died.-Monthly Journal of Medical Science for October, 1847, p. 238.

Dr. Fenwick has collected together, from civil and military practice in Great Britain, America, and France, a list of four thousand nine hundred and thirtyseven amputations of large limbs. Of these patients, a thousand five hundred and sixty-five died, or nearly thirty-two in a hundred.

\section{EXCISION OF JOINTS.}

The excision of diseased joints, as a substitute for amputation, which was revived a few years ago by Mr. Syme,-more particularly for the elbow and shoulder,-has lately been practised on most of the larger joints of the body, and has passed into surgery as one of the established operations. The excision of the knee, in particular, has been much more frequently performed than that of any other large joint ; the diseases which, in civil practice, require surgical interference, being much more frequent in the case of the knee than of the elbow. By this operation, many limbs, which would otherwise be condemned to amputation, are saved, and made useful to the patient. Excision is, of course, applicable only to cases in which the limb is otherwise sound, and the movements of the hip and an- 
kle unimpaired. Performed upon adults, it already counts a great number of most admirable results: but, in the case of young children, a very grave objection has arisen from the fact that in several instances, at first reported as successful, the growth of the limb has been arrested; leaving it, at last, many inches shorter than its fellow. There is no doubt, that, if the epiphyses of the bones are wholly removed, the subsequent growth is more impaired than when they are preserved. It is therefore proper, in children, to pare off from the articular surfaces as thin a slice as is consistent with the removal of the diseased bone and the whole articular cartilage. In one case in my own practice, in a little girl of about eight years of age, an entirely useless and bent-up limb, the result of scrofulous white swelling, was made serviceable by removing the ends of the bones, and straightening the joint. I saw this patient, at the end of three years, perfectly well, and walking with a slight limp. The limb was shorter than the other; but the pelvis had so adapted itself as to make the loss of length less evident than might have been expected.

I have performed excision of the knee-joint three times with most gratifying success. In a fourth case,-that of an adult female,-which, from the first, seemed a less promising one for the operation than the others, amputation was afterwards necessary.

In two or three excisions of the shoulder-joint for caries, the results have all been successful.

The advantages of excising the head of the humerus and the articular surfaces entering the elbow- 
joint are undoubted. The decision in the case of the knee-joint can be hardly yet considered as finally made.

\section{CANCER.}

The question of the removal of malignant tumors by surgical operation has been a subject of discussion from the time of the father of medicine. It was the opinion of Hippocrates, that the disease had much better be left to itself; and that the patients died sooner when the attempt was made to remove it, than when it was allowed to pursue its natural course. The same views, substantially, have been held, until within a few years, in England and the United States.

In a report made to the American Medical Association in 1852, supported by cases which had occurred in my own practice, I felt justified in drawing the following conclusions: first, that, in a certain number of cases, cancerous tumors, once removed, do not return ; secondly, that, in certain other cases, the patient, after an immunity for a longer or shorter period, has a return of the disease, requiring a second operation, which sometimes proves successful; thirdly, that although, in a great proportion of cases of extirpation, the disease returns, either in the neighborhood of the wound or in some internal organ, yet, even under these circumstances, it generally re-appears in a less loathsome form, and is attended with much less suffering, than if the original local disease had been allowed to proceed to a fatal termination ; fourthly, in consequence of the immu- 
nity from pain afforded by the use of anæsthetic agents, one of the most serious of the old objections to extirpation no longer exists.

After an experience of ten years since this report was made, I feel even more fully convinced of the propriety of removing cancer,-particularly of the breast, - except in cases of marked impairment of the health from the disease, or when there is evidence of decided constitutional infection; and this opinion would be justified, even if we admit that the disease is never really destroyed by surgical removal. I am fully confident, however, that, in a certain number of instances, the disease is radically extirpated by the operation. There are still living, and in good health, several patients upon whom I operated for undoubted malignant disease ten or fifteen years since. I have also a patient, now in a state of perfect health, in whom the disease occurred five separate times within two years, and was as often removed; the last time, more than two years ago. In another case, operated on in 1859 , in which a large scirrhous tumor of the breast was rapidly approaching the surface, the whole disease was removed, and the patient recovered her health. At the end of eighteen months, a tumor appeared in the axilla; which, after attaining the size of an apple, was enucleated from among the great vessels and nerves. At the end of a year, a hard tumor, imparting almost a bony sensation, appeared near the spinous process of one of the dorsal vertebræ: this was also removed ; and the patient finally died, with cerebral symptoms, four years after the first operation. During 
all this period, she was cheerful; and most of the time was able to take long journeys, and to enjoy the society of her friends: the question of cancer was never mentioned between herself and her surgeon. This is an extreme case; and perhaps some might question the choice between a large ulcerated sloughing cancer, and the alleviation, both mental and physical, afforded by an operation. . In regard to the propriety of operating for the removal of epithelial cancer, of course there can be no question; cases of cancer of the lip and of the face being of constant occurrence, in which there has been no return of the disease even after the lapse of many years after removal.

The cancers of the breast, which, according to my experience, have been the most painful, rapid, and least amenable to surgical treatment, are those developed during lactation; and they often occasion great embarrassment in diagnosis. The breast swells, becomes indurated, and gives all the appearance of an obstruction in the lactiferous ducts : in spite of remedies, however, the hardness increases; the skin becomes rough and brawny, and the whole organ solidly fixed to the ribs; cancerous tubercles appear in the vicinity, and the patient often dies with either cerebral or spinal symptoms. The wound made by the removal of a tumor of this kind is very large, involving, as it does, the loss of the whole integument over it. I have once or twice operated for this disease, -at the earnest solicitation of the patient, on account of intense pain,- -dressing the wound 
afterwards with flour; which I had first seen used for a similar purpose, in this city, by the late Prof. George Hayward, and which avoids the necessity of subsequent exposure to the air during the dressings.

It is not unworthy of notice, that in removing large tumors on the left side of the chest, over the region of the heart, great depression of the vascular system, attended with symptoms of collapse, is often seen to occur from the exposure of the large surface to the air ; the symptoms disappearing as soon as the wound is covered. I have therefore made it a rule, while the vessels are being secured, to expose only as small a portion of the wound as is absolutely necessary.

The question of the destruction of malignant disease by means of caustics is one of much interest, the practice having found both advocates and opponents among men most distinguished in the surgical art. Great mischief is done in this way by charlatans, who make use of caustics for the destruction of all kinds of tumors, innocent as well as malignant, whose removal they would never dare to attempt with the knife. The chief objection to the use of caustics, in all but a few exceptional cases, is the extensive destruction of integument, which often renders the cure very slow and imperfect. In cases of small or superficial cancers, especially of the epithelial variety, caustics sometimes answer a good purpose ; but if the tumor is large, or deeply seated, the process is both tedious and disgusting. If inefficiently employed, they appear to do great harm by stimulating the growth to increased action. 
The most efficient caustic, perhaps, is the chloride of zinc, made into a paste with flour, and planted well down into incisions made with the knife. Another, advocated by Velpeau, and I believe also by Mr. Syme, consists of strong sulphuric acid, mixed with charcoal or some vegetable powder.

In connection with the etiology of cancer, I would say, that I have had several well-marked cases, in which the diathesis was evidently awakened by a blow; the patient subsequently dying of malignant constitutional disease.

\section{PLASTIC OPERATIONS.}

It was my good fortune to witness a very large number of plastic operations by the distinguished $M$. Dieffenbach, of Berlin, at the time of his visit to Paris in 1834. By invitation of the leading French surgeons, he gave a most instructive exhibition of his great skill in restoring lost portions of the face, especially the nose; operating, during many days in succession, upon large numbers of patients, collected for the purpose from the various quarters of Paris: thus performing, in the course of a few weeks, a greater number of these then novel operations than most surgeons would ordinarily see in a lifetime. His rhinoplastic operations were all performed by the Indian method, in which the material for the new nose is taken from the forehead.

Soon after my return home, I had an opportunity of performing several operations for the restoration of the nose; employing, in one case, the Taliacotian 
or Italian method, in which the nose is formed from the integument of the arm; and, in another case, taking the requisite material from the fore-arm. (I refer to these cases as being the only ones ever attempted in this country; and with the exception, perhaps, of one or two instances in Germany, almost the only successful ones since the time of the inventor.) The Indian method I have very frequently employed ; in most cases, with excellent results. The scar left on the forehead is much less conspicuous than might be expected; and the great suffering to the patient, which results from the confinement of the arm to the head in the Italian method, is avoided. The principal inconvenience which I have observed in these operations depends upon the fact, that the material for the septum, and often of the tip of the nose, must be taken from the scalp. The consequence is, that the hair continues to grow upon these parts ; requiring frequent shaving, or extraction with forceps. Depilatories I have often tried, but have never found that they produce more than a transient effect.

One of the most important applications of plastic surgery is in the treatment of contracted cicatrices following severe burns, or extensive destruction of integument from other causes. In these cases, mere division of the cicatrix is of no permanent benefit; but by the total removal of the diseased tissue, and the transplantation to its site of a flap of sound skin, the use of the part is often completely restored. After the removal of cancerous growths, also, it is often highly advantageous to fill the opening by 
means of a flap of sound integument, instead of waiting for the slower and less perfect cure by cicatrization.

OPERATIONS FOR FISSURE OF THE SOFT AND HARD

PALATE.

The operation for fissure of the soft palate was first successfully performed by Roux, in 1819 ; and shortly after, in this city, by Dr. J. C. Warren, with whom, also, the idea was original. After the publication of M. Roux's cases, it appeared that a similar but unsuccessful attempt had been made two years before by Graefe ; who, however, contented himself with freshening the edges of the fissure by caustic, instead of by cutting instruments, as employed by Roux and his successors. The simple fissures of the soft palate, to which alone the original operation was considered applicable, do not probably exceed one-tenth of the whole number of cases of cleft palate; and are, of course, those in which the need of relief by an operation is least urgent. M. Roux soon attempted to extend the application of his operation to cases of more extensive fissure by cutting away the soft from the hard palate at the posterior margin of the palate-bones, and so effecting the somewhat more perfect co-aptation of the margins of the fissured velum, but leaving a large triangular hole in front still unfilled. This operation was apt to fail, owing to the division of the vessels which nourish the flap; and was never very generally adopted by operative surgeons.

The idea had early occurred to me, that, in these 
cases, a much more perfect operation might be performed by dissecting or peeling up the soft tissues from the roof of the mouth, and thus making a continuous flap, extending from the anterior extremity of the fissure in front to the tip of the uvula behind. This operation I performed with success, and published several cases in the "New England Quarterly Journal of Medicine and Surgery" for April, 1843, and in the "American Journal of the Medical Sciences" for the same year. Another even more important improvement, which I introduced and published at the same time, was the division by the scissors, first, of the posterior pillar of the palate, which is made up chiefly of the fleshy fibres of the palato-pharyngeus muscle ; and, secondly, of the superior palatine muscles, - the tensor and levator palati, - which, on stretching the palate, are felt in bold relief above and behind the velum. By the division of these parts, the velum is perfectly relaxed ; thus immensely facilitating the subsequent stages of the operation, and relieving the stitches from all injurious tension. The operation, as thus improved, has become one of very frequent performance, and of great certainty in its results.

Of late years, in consequence of the improvements which have been made in the art of mechanical dentistry, I have, for the most part, ceased to operate for the closure of the anterior part of the fissure; contenting myself with the establishment of the arch of the soft palate, and perhaps also covering the fissure in the bones as far forward as the point of junction of the maxillary with the palate bones. In 
these cases, it is, of course, necessary to complete the roof of the mouth by means of a plate of gold or other suitable substance; but this inconvenience is more than compensated by the diminished severity of the operation.

- The great object aimed at in these operations is to establish the arch of the soft palate. If this is effected, a good result may be confidently predicted as soon as the remaining fissure is covered by the gold plate, and the patient has learned to use his newly acquired organ in articulation. If, however, the union fails at the posterior part of the line of suture, so as permanently to leave even a slight fissure there, the cure will be more or less imperfect.

I have now operated about ninety times for cleft palate; and, with the exception of perhaps half a dozen cases, I have never failed to get more or less union of the soft parts; and it is a remarkable fact, that, in the most extreme cases of very wide fissure, the operation has been as successful in improving the voice as in cases of the simplest character confined to the soft palate only. The most essential point is, I am sure, to establish the velum throughout the greatest possible extent; and just in proportion as this end is attained will be the degree of perfection with which articulation will be finally performed.

\section{OPERATIONS FOR HARE-IIP.}

The proper time and the best method of operating for this deformity are still open questions in surgery. It was the opinion of Dr: John Warren, that 
the operation should be performed at a very early period; and the same practice was strongly advocated by Dr. A. L. Peirson of Salem, who published a paper upon the-subject. I have often done it within twenty-four hours after birth, putting the child to the breast as soon as the mother's milk is secreted. The act of sucking in no way interferes with the co-aptation of the parts, but rather contributes to their more perfect apposition. Two or three days after birth, a peculiar hemorrhagic tendency is frequently observed, accompanied by an icteric hue of the skin, which passes off in the course of a fortnight. If, therefore, the operation is delayed beyond forty-eight hours, it should be postponed for two or three weeks longer, or until the processes of diges- tion and nutrition have become well established. Before I commenced practice, the figure-of-eight suture, with pins, was in general use in this vicinity, causing much irritation, and thus often defeating the objects for which it was employed. I early adopted the plan of using simple sutures instead of pins; and either made no application to the wound, or dressed it with a bit of wet lint. I also introduce a single stitch on the inner edge of the lip, cutting the ends very short. Plasters and bandages I have entirely given up, as causing irritation, and confining foul secretions.

The plan of kecping the child at the breast during the period while union is taking place, I consider a very great improvement over the old practice of feeding ; preventing, as it does, that disturbance in the digestion which so often proves fatal to the adhesive process. 
VESICO-VAGINAL FISTULA.

The treatment of this affection, which had, until very recently, been almost wholly confined to the simplest cases, has been lately revived in this country with remarkable success, especially since the publication, by Dr. Sims of New York, of a number of very successful cases, in which he attributed the good result to the employment of sutures of silver wire. For a time, metallic sutures were held in high estimation, and were employed in almost all departments of operative surgery; but a more extended trial has failed to demonstrate that superiority which was claimed for them over silk or linen threads, and the greater inconvenience which attends their employment has already led to their abandonment by some of the best surgeons.

The real improvement in this operation, and that which has been the means of bringing it into so general use, is the very free dissection of the vaginal mucous membrane from the old cicatricial tissue and from the walls of the bladder: by this plan, the stitches are effectually relieved from tension, and the results are generally favorable.

In many cases of this disease, we find the os uteri, and sometimes the upper part of the vagina, completely obliterated; causing retention of the menstrual fluid. I have watched a number of cases of this kind, and have always observed that relief is ultimately obtained, often after great suffering, by the formation of a fistulous opening communicating with the vagina, or, very rarely, with the bladder. 
In quite a large number of operations which $I$ have performed for vesico- and urethro-vaginal fistula, as well as in all that I have done for cleft palate, I have always used sutures of common surgeon's silk, and have had every reason to be satisfied with the results.

Few surgical diseases are more distressing to the patient than vesico-vaginal fistula, and no operation better rewards the skill of the surgeon: rescuing the sufferer, as it does, from a state in which existence has become a burden, and restoring her once more to the world and to the enjoyments of social life.

HIP AND SPINAL DISEASES.

The present improved method of treating hip and spinal diseases may be adduced as one of the greatest triumphs of the modern school of pathology. Hipdisease, as every one knows, was formerly treated almost exclusively as a local inflammation; and the patient was confined to his bed, tormented in turn by the severe pain caused by every motion of his diseased joint, and by an appalling routine of leeches, cups, blisters, setons, and issues. Dr. Physick, of Philadelphia, demonstrated the great importance of rest; which he secured by means of the "carved splint," accurately fitted to the hip, and confined by bandages. The carved splint is, however, an expensive appliance, requiring, as it does, to be made expressly for the case in which it is to be employed. The full benefit, therefore, of this treatment was only realized after the introduction of splints of gutta percha, at our hospital, some ten or twelve years 
ago. The rest thus secured by the immobility of the apparatus affords immediate relief from pain, and, with the aid of baskets which I have had made for the purpose, admits, even in bad cases, of the patient being readily carried into the open air, or even transported to great distances. The very recent invention of the improved instruments of Drs. Davis and Sayre, which, in many cases, admit of a moderate degree of locomotion, has given a new impetus to the treatment of this disease, avoiding, in even a greater degree than before, the injurious confinement in bed to which the patient was formerly condemned. The constitutional treatment must, of course, be directed to the preservation of the strength during the course of a long and tedious disease; and it is by the mechanical appliances just mentioned that we are enabled to avail ourselves of the inestimable benefits of fresh air and gentle exercise, so essential to the maintenance of health both of body and mind.

Caries of the spine naturally falls into the same category as hip-disease : mechanical support should be given to the back, in order to prevent the breaking-down of the diseased vertebræ from the weight of the upper part of the body: the patient is thus enabled to move about, and preserve a fair degree of health during a long and trying disease.

Many affections of the knee, and other large joints, are to be treated according to the same principle; sustaining the system by invigorating remedies, and securing immobility of the diseased joint by proper mechanical appliances. 
It is still a question, how far we can safely venture in attempting to destroy the adhesions, and consequent immobility, caused by disease of the hip and other large joints. Some experiments have been tried, with a view to deciding this point; but the rule of practice is, as yet, by no means settled.

TUMORS OF THE UPPER AND LOWER JAW-BONE.

Operations for the removal of large tumors of the jaws were formerly very rare, and were considered highly dangerous. By the use of improved cutting forceps, of large size, the upper jaw-bone may now be removed with but little trouble or danger; being, in fact, a less formidable operation than the excision of the lower jaw. The deformity, too, is much less than might be expected ; as the cavity is, in a measure, filled by adventitious tissue. Some of the nonmalignant tumors of the lower jaw, though of very formidable appearance, are best treated without removal of the bone: I refer particularly to large cystic tumors, in which the horizontal ramus and ascending portion of the jaw are expanded by the morbid growth, so as to leave but a thin shell, almost wholly destitute of osseous substance. In two of these cases, by excising a portion of the tumor within the mouth, breaking down its parietes, and keeping up a certain degree of irritation afterwards by injections, I have succeeded in overcoming the tendency to the reproduction of the cyst; and have seen new bone deposited, so as to restore the jaw for all useful purposes. Prof. Gross of Philadelphia, in his excellent work on Surgery, and Prof. March 
of Albany, have also insisted on the importance of saving the jaw in this disease.

\section{CROUP.}

About twenty years ago, I was called to operate several times upon children in the very last stages of croup. Tracheotomy was performed, with immediate relief to the suffocation, and for a few days the result seemed almost miraculous ; but the lungs had already become affected, and the vital powers so weakened, that the cases all terminated unfavorably. What was needed, in fact, was the earlier performance of the operation, before the system had received a fatal shock; and to this end it was necessary that not only the medical profession, but the public also, should be convinced that there is little or no danger in the operation, when skilfully performed. I have performed tracheotomy in a great number of cases, and have witnessed many operations done by others; and have never known a single instance in which death could be ascribed to it. Tracheotomy, in croup, has lately been revived by one of our number,-Dr. George H. Gay; and the practice has been successfully followed by many other members of this Society. What appears to be especially required in the after-treatment is, that the air for respiration should be kept warm and moist, and that the patient should never be left without a competent medical person in attendance to act instantly in case of a sudden obstruction of the tube. The use of ether very greatly facilitates the performance of this operation, and appears not to cause any 
additional risk. For the investigation of the nature and treatment of this important disease, we are especially indebted to the labors of our late distinguished colleague, Prof. John Ware, whose admirable paper may be found among the official publications of this Society.*

\section{VASCULAR OR ERECTILE TUMOR.}

This disease has been admirably described and depicted by John Bell, who named it Aneurism by Anastomosis. The name, erectile tumor, is given to it on account of the striking analogy which it presents in structure with the erectile tissue found in certain parts of the body in man and in most of the higher animals. Erectile tumors are made up almost wholly of greatly enlarged blood-vessels; and are divided into arterial and venous, according as one or the other class of vessels seems to predominate. The arterial tumors, which are altogether the most formidable, are often of very rapid growth, and are marked by active pulsation. The venous tumors are more indolent, and often impart to the touch the feeling of a fatty growth : they may, however, be partially emptied of blood by pressure, and thus temporarily reduced in size. It is a common characteristic of erectile growths, that they become enlarged and turgid during any act which obstructs the free return of the blood to the heart,- such as coughing, crying, laughing, \&c., - contracting again to their former size when the patient becomes quiet.

\footnotetext{
- Contributions to the IIistory and Diagnosis of Croup. By JoHN WARE, M.D. New England Quarterly Journal of Medicine and Surgery, vol. i. p. 193.
} 
The treatment of small erectile tumors is very. simple, and may be either by excision or by the ligature. In excising them, the absolute rule is that laid down by John Bell, - " not to cut into them, but to cut them out." In operating by the ligature, it is essential that the whole growth should be thoroughly strangulated, and that no diseased tissue be left behind. If, in the attempt to excise the tumor, it is unfortunately cut, the whole growth should be immediately included in a ligature, and allowed to come away by sloughing. I have several times treated erectile tumors of the face by repeated small cauterizations with nitric acid. I have thus succeeded in destroying the whole morbid tissue piecemeal, without the loss of substance, and consequent scar which follows excision or the ligature. Injection of the growth with per-chloride of iron has also been employed, in many cases with success; but death has occasionally resulted from the practice.

The operation for the cure of extensive disease of this kind is one of the most formidable in surgery, owing to the liability to dangerous or even fatal hemorrhage. In two cases, where large pulsating tumors occupied nearly the whole forehead and upper part of the head, I have surceeded in destroying them by a series of operations, in which the afferent vessels were obliterated by strong ligatures tied over pins passed beneath them, and thus the whole circumference of the growth thoroughly strangulated. By the application of new ligatures as often as any return of the pulsation was detected, and by the free use of styptics and escharotics, the disease was finally 
extirpated. In another case, which I published about twenty years ago, I tied both the carotid arteries for an immense erectile growth which occupied the lower lip and a large part of the face and neck. The result of this operation, which was then only the third or fourth in which both the carotid arteries had been successfully tied, was perfectly satisfactory. A part of the lower lip, which had been the seat of an ulcerated and bleeding tumor, was afterwards excised without troublesome hemorrhage; and, on seeing the patient two years subsequently, the vascular tissue was found to have wholly disappeared. In a pulsating tumor of this character, occupying the palm of the hand, and held, as it were, like a ball in its grasp, the tumor gradually increased, and finally involved nearly the whole upper extremity. - The limb was amputated near the shoulder, in time to save the life of the patient, although the erectile tissue had partially invaded the structure of the part, and many ligatures were required to arrest the bleeding. The specimen, which shows a direct continuity of the largely dilated arteries with the venous trunks, was beautifully injected and prepared by Dr. R. M. Hodges, and may now be seen in the Warren Anatomical Museum. I have also had lately under my care a girl, nineteen years of age, with a large venous erectile tumor, occupying nearly half the cavity of the mouth, and hanging down from the lower lip: it also included nearly half of the tongue, and at times seriously affected deglutition and respiration. I operated on this case by the ligature, tying both the tumor of the cheek and that of the tongue 
on the same day. The ligatures came away at the proper time, and the result was fully successful.

I have spoken thus at length of this disease, on account of its rarity, and from the fact, that, owing to the absence of pain, it is too often neglected until it has acquired enormous proportions. In such cases, it is rarely to be cured by a single operation, but requires a patient and persevering use of needles, ligatures, caustics, and sometimes, although very rarely, the knife, before it can be completely extirpated.

A word may be added upon the treatment of aneurism by compression, which has been lately practised with success in many formidable cases, which must otherwise have been submitted to the severe and dangerous operation of tying the artery. The compression may be made either with the fingers, in which case it is kept up for several hours by relays of assistants, by long-continued and extreme flexion of the limb, or by special instruments contrived for the purpose. In two cases of very large subclavian aneurism, which I have treatcd by the direct pressure upon the tumor of a heavy weight, in the shape of a cannon ball, and where the Hunterian operation was impossible, I have been so fortunate as in one instance to effect the complete obliteration of the artery; and, in the other, to producc coagulation of the contents of the sac, followed by suppuration and sloughing, and ultimately by the perfect cure of the discase. 


\section{VARIX AND VARICOCELE.}

Many methods have been suggested for the cure of varicocele, or enlargement of the spermatic veins. Breschet's method, with the screw-clamp, was almost insupportably painful; while that of Ricord, which is now perhaps the favorite one, consists simply in cutting across the packet of veins with a ligature. I have tried both these plans, as well as that by removing a portion of the scrotum; or, in cases where it has been much elongated, by producing adhesions of its sides by means of sutures.

The following operation, which I have successfully performed in from sixty to seventy cases, and which is, I believe, peculiar, seems to me to be the simplest and most effectual. The vas deferens is first separated from the vascular part of the cord, and is kept out of the way by an assistant. A longitudinal incision, of about two inches in length, is next made in the scrotum, down upon the bundle of veins, which is then seized with the forceps, drawn out, and, by a few touches of the knife, separated from the adhering tissues. Two strong ligatures are now passed, and firmly tied above and below the mass of enlarged veins, so as to include between them as much of the diseased tissue as possible. The strangulated veins, which at once shrink into a very small compass, are now allowed to recede into the wound, which, by the contraction of the scrotum, becomes reduced to a comparatively small size. The patient is confined to his bed, and water-dressings applied during the separation of the slough, which takes 
place in from ten to fourteen days. In several cases, where the scrotum has been elongated to double its natural length, and filled with large masses of veins, which would seem almost to defy any mode of treatment, I have operated by this method with perfect success, and have seen the scrotum contract within a few weeks, or, at most, a few months, to its normal size.

Varicose veins of the extremities have been treated by a multitude of operations; among which may be mentioned incision, ligature, caustic, and, latterly, injection with the per-chloride of iron. The method which appears to me to be the least liable to objection is that of passing a pin directly under the vein, and placing a ligature, in the form. of a figure-ofeight, over it: this may be retained in place for three or four days, or until a disposition to ulceration is manifested, when the compression may be relaxed by removing the thread, but leaving the needle for some days longer. Mr. Henry Lee, of St. George's Hospital, London, has, I believe, proposed a modification of this method, which would seem to be an improvement. He applies two needles, in the manner just described, at a distance of about two inches apart, dividing the veins between them by subcutaneous incision with a common tenotome.

\section{RADICAL CORE OF HERNIA.}

Within the last twenty years, operations for the radical cure of hernia have attracted considerable attention; and for a disease so extremely common, and so very inconvenient, and in some cases even 
dangerous, it is remarkable that no safe and effectual operation has yet been discovered for its relief. In 1852, Dr. George Hayward, Dr. S. Parkman, and myself, were appointed a Committee of the American Medical Association to prepare a report on this subject. In that paper, I mentioned a number of cases of small herniæ which had been treated with success by the injection of stimulating liquids in the neighborhood of the neck of the sac, in the manner practised by the distinguished Prof. Pancoast of Philadelphia. In some of these cases, as I have since been able to convince myself, the cure was permanent. Since then, many different methods have been proposed, some of which I have tried with success. The one most in favor at the present moment is that by Mr. John Wood, of King's-College Hospital, London, which has been several times performed in this city. It consists, essentially, in the constriction and partial obliteration of the inguinal canal by means of a subcutaneous suture or ligature. Mr. H. Lee has, I believe, professed to obtain the same result by the passage of a small seton through the track of the hernia, confining the patient to his bed, and retaining the sides of the canal in contact by the pressure of a truss. The seton is left in place for a few days only; the precise time being determined by the degree of irritation produced.

A single remark should be made upon strangulated hernia with reference to the proper time to operate for its relief. If moderate efforts at taxis fail, even after the full muscular relaxation afforded by the inhalation of ether, no farther time should be lost, but 
we should proceed at once to the operation. The danger of the operation is certainly much less to be feared than the violent bruising of the parts by rude attempts at reduction; and I may say, as I have already said of tracheotomy, that I have never seen a case of death following the operation which could not obviously be attributed to some other cause.

PERINEAL SECTION.

On my second visit to Edinburgh, in 1855, after the lapse of about twenty years, I had an opportunity of again seeing Mr. Syme, the distinguished surgeon, still in full fame and vigor. One of the operations, in particular, which, by his invitation, I then witnessed, has been now adopted by surgeons in different parts of the world, and its utility fully established: I mean that of perineal section for inveterate stricture of the urethra. It is well known that old and callous strictures in many instances, however often and fully dilated, tend constantly to relapse, and are sometimes followed by very painful and dangerous consequences. In such cases, by cutting down in the perineum, dividing the adventitious tissues freely, and introducing a properly, sized instrument of gum elastic, a new canal, not liable to future degeneration, is formed over it. In a number of cases which have come under my own observation, the urethra has been so nearly obliterated, and the small passage through which the urine dribbled has been so tortuous, and the symptoms so urgent, that it has been necessary to proceed at once to the operation, unguided by any instrument in the urethra. 
This procedure is, under such circumstances, exceedingly laborious, especially where the stricture is complicated by numerous fistulæ and old callosities in different parts of the perineum: still I have never been defeated in the attempt to find the urethra, and all the cases have resulted in the relief of the patient. This operation, which is now very frequently performed for the cure of partial obliteration of the urethra, occurring both from accident and disease, may be made in many cases also-such as those mentioned above-to take the place of puncture of the bladder through the rectum.

I have also seen numerous cases operated on by internal division by Civiale; but the results were certainly not so striking as in the cases treated by Mr. Syme.

\section{INJURIES OF NERVES.}

Since the beginning of the present war, I have had occasion to treat several soldiers for severe neuralgia following gunshot injuries of large nerves. In these cases, the pain was so intense as to deprive the patients of sleep; and had continued in one instance for several months, in spite of various local applications of greater or less severity. The question was raised as to the propriety of dividing one or more of the large nerves of the arm ; but, in the absence of recorded cases undertaken for this object, it was thought best first to try milder measures. In one case, where the median nerve was evidently entangled in a mass of dense cicatricial tissue, it was carefully dissected out, with the effect, for a time, of 
completely relieving the pain ; but, on the re-establishment of cicatrization, this symptom returned, although in a much less degree than before. The other cases-two in number, which, with the first, I have already published-were also dependent, probably, upon changes which had taken place in the tissues immediately surrounding, in one case, the median and radial, and, in the other, the sciatic nerve. The most rational hope of a cure evidently lay in waiting for the completion of the natural processes of repair, provided only that the pain could be held sufficiently in check to admit of the requisite delay: this problem was very happily solved by the use of daily hypodermic injections of morphia; which, in one case, were continued for nearly six months, without seeming to impair the health or appetite. The dose of morphia administered in this way did not exceed half a grain a day, and did not require to be increased, as is generally the case when given by way of the stomach. No attempt was made to inject in the immediate vicinity of the nerve ; and in numerous instances in which the operation was performed on the opposite limb, or even in distant parts of the body, the experiment was equally successful.

\section{OVARIOTOMY.}

The extirpation of large ovarian tumors has been occasionally practised for a long time. Within a few years, the operation has been revived in England and in this country with remarkable success ; many patients, otherwise doomed to a lingering death, hav- 
ing been completely cured by it. The great obstacle to the more free performance of ovariotomy is the hesitation which the surgeon feels to advise, or even to permit a patient, in the enjoyment of moderate health, to undergo, an operation which may almost immediately prove fatal. In itself, ovariotomy is not more dangerous than many of the recognized cavital operations; the difference being, however, that these last are done in a pressing emergency, while ovariotomy is not. The proper course of practice would therefore seem to be, to make a fair statement to the patient and friends of what they have a right to expect from the operation, leaving to them to decide for themselves. I have once been completely successful in the treatment of an enormous unilocular cyst of the ovary, in which respiration was impeded, the limbs edematous, and the patient rapidly failing, by evacuating the cyst, and leaving the canula in position; making occasional use afterwards of iodine injections.

The only point to be especially noticed in the manner of performing ovariotomy is the method of securing the bleeding vessels of the pedicle. The plan now most in favor is by drawing the stump out of the wound, and compressing it in a clamp made for the purpose. This proceeding, however, is sometimes attended with severe pain, especially if there is much tension of the parts. Prof. Simpson, of Edinburgh, has lately recommended " acupressure" as a substitute for the clamp, and claims for it substantial advantages.

The treatment of large fibrous tumors of the uterus 
by enucleation, is another of the many valuable surgical improvements for which we are mainly indebted to the fertile invention of the distinguished Professor of Obstetrics in the University of Edinburgh.

I have recently operated with success upon a remarkable case of hypertrophy of the os uteri, with excessive elongation of the cervix; - a disease which has been generally confounded with prolapse of the organ, but which has been very recently investigated by $M$. Huguier, who has published an elaborate monograph upon the subject. In this case, as in several described by Huguier, the external tumor was larger than a goose egg, and consisted not only of the enlarged os, but also of a considerable portion of the bladder in front, and a large cul-de-sac of the peritoneum behind. The treatment consisted in the careful dissection of the os and cervix from the adjacent organs, dividing the cervix at as high a point as could be conveniently reached. The other organs being thus relieved from the dragging effect of the tumor, immediately returned to their normal positions; the cure was complete.

\section{ORTHOPEDIC SURGERY.}

The division of tendons for the cure of deformities, as instituted by Stromeyer, has come into general use within the past thirty years. Almost all the tendons, and, I may say, muscles of the body, have been divided, with this object in view. The beautiful operation of Dieffenbach for strabismus has lately been greatly improved by dividing the tendon as near as possible to the cornea, and stitching up the 
wound afterwards. The division of tendons, assisted by ingenious mechanical contrivances,-which has been nowhere practised with greater success than in our own city,-has been made to yield results seemingly almost beyond belief. These cases, however, require great skill in operating, much ingenuity in adapting apparatus, and great patience in using it; and no surgeon, not possessed of this latter virtue, can hope to attain any great success.

It has been contended very lately in England, that most of the cases for, which tenotomy has usually been performed may be equally well treated by mechanical appliances alone. The truth probably lies between the two extremes of practice.

\section{REMOVAL OF TONSILS.}

For a minor operation, perhaps none affords so much relief, and has so much effect on the constitution, as the removal of enlarged tonsils. The patient, with a half-strangled respiration, the chest deformed, pale, trembling, and subject to exhausting perspirations, - I allude to extreme cases,-by the removal of these tumors, regains a free passage for the air to the lungs; the good effects of which are at once shown by increased vitality, improved nutrition, and restoration of color. The tonsils were formerly either excised by the knife, or removed by the ligature; both operations being of such importance as to be undertaken with considerable dread. Excision was often followed by severe hemorrhage; and the removal by the slow action of the ligature, with the attendant swelling of the throat and the putrid 
exhalations, is almost too bad to be mentioned. By the simple guillotine instrument,-introduced by Dr. J. C. Warren,- the operation may be performed without danger, and hardly compels the patient to abstain from a single meal. I have performed this operation from five hundred to a thousand times, and have never lost a single patient from it, nor had a single case of dangerous hemorrhage. In two instances where I have seen it done by the modification of Fahnestock's instrument, - which requires the tonsil to be fixed with a fork, and the section made by drawing the knife instead of pushing it,-I have known troublesome bleeding to occur. The reason is, that, in this manouvre, the knife requires to be very sharp, to prevent the tonsil from being torn up, so to speak, by its roots: whereas, by the simpler guillotine, the tonsil is, in the first place, not drawn out from the side of the throat; and, secondly, is partially jammed rather than cut off,--thus affording an additional safeguard against hemorrhage.

In the "Philadelphia Medical Examiner," April 6,1839 , I published an account of certain deformities of the chest, which might be attributed to enlarged tonsils, obstructing the passage of air, and preventing healthy respiration. This malformation has been previously described by Dupuytren, but was not attributed by him to its proper cause. The form of the chest at once begins to improve on the removal of the obstruction to the respiration. 


\section{ARTIFICIAL ANUS.}

A more distressing and loathsome malady can hardly be conceived than the constant discharge of fæcal matter through a fistulous opening on the outside of the abdomen. It is to Dupuytren, ever fertile in expedients, that we owe the very ingenious method of treating this affection by destroying the projecting spur of intestine before attempting the closure of the external orifice. I have been consulted in a number of cases of artificial anus, resulting both from accident and from disease, and in two cases which I have treated I have obtained most satisfactory results. In one of these cases, the external opening was entirely closed and the cure perfect; in the other, also, the continuity of the intestine was restored, but a fistulous aperture remained, through which a small quantity of serous fluid only was discharged.

The instrument which I have employed for the destruction of the spur of intestine is much smaller and lighter than that of Dupuytren; it is therefore much more easily retained in position, and avoids the heavy dragging action upon the parts which often gives rise to great suffering.

\section{ECRASEMENT LINEAIRE.}

Within a few years, we have heard of the introduction in France of the écraseur ; by which, instead of cutting the tissues with the keen edge of the bistoury, it is proposed to divide them by a slow process of crushing, and thus to remove tumors, amputate 
limbs, and, in fact, perform almost all operations hitherto done with the knife. The supposed advantages of this method are, the prevention of hemorrhage, and the diminution of the risk of purulent absorption, by closing up the great venous trunks. For the former of these reasons, this instrument will be occasionally used where great danger from bleeding is anticipated, as in the case of vascular tumors, internal hemorrhoids, and in the removal of large portions of the tongue, \&c. In other cases, however,-such as the excision of breasts, opening of abscesses, lithotomy, and many other operations usually done with the knife,-its use will hardly extend beyond the wards of its inventor.

It is impossible, within the limits of this address, even to enumerate the important improvements which have been made in the science and art of surgery during the last quarter of a century. I have therefore confined myself to the discussion of a few prominent topics; selecting those in which, as it has appeared to me, the changes of practice have been most marked. Amid the varied distractions of active professional life, many valuable discoveries are for a time neglected; and we are all apt to look with especial regard upon such subjects as have been more particularly connected with our own pursuits. This brief sketch, therefore, of recent surgical progress, must, after all, be considered as but an imperfect review of a few chapters of individual experience, rather than a true record of the real advancement of our art. 
I cannot omit a brief allusion to the vast field for surgical improvement opened by the gigantic war in which we are now engaged. From a very early period, great efforts have been made by the Government to secure accurate reports of the work done by its medical officers, and to collect upon a large scale specimens illustrative of the wounds inflicted by the deadly missiles of modern warfare. The collection and publication of these statistics cannot fail to throw light upon many important points both of practical surgery and of military hygiene; but, for the full benefit to be derived from such studies, we must wait for the leisure of returning peace. Meanwhile the duties of the camp and hospital are impressing, upon the minds of a thousand laborers, lessons of practical experience which cannot fail to exert a marked influence upon the future literature of our profession. All praise is due to the members of our medical corps, summoned hastily from private life to scenes of new and untried labor; and who, by the fidelity and enthusiasm which they have shown in the performance of duty, have more than atoned for early lack of military training.

In this connection, a passing tribute is due to those members of our Society who have devoted their lives and energies to the service of their country in her hour of trial. Through the wise foresight of his Excellency the Governor of this Commonwealth, at the very commencement of the war, a Board of Medical Examiners was created, in order that the qualifications of every candidate for the position of surgeon or assistant surgeon to our regiments might 
be thoroughly and impartially tested. Aided by their judgment, and seconded by the untiring energy and patriotism of our deservedly popular Surgeon-General,* he has, by a wise exercise of the appointing power, made the name of Massachusetts surgeons honorable throughout the length and breadth of the land; and has added another to the already numerous proofs as well of his enlightened appreciation of the benefits of thorough scientific training, as of his conscientious and consistent devotion to the cause of humanity.

To one, especially, of our number $†$ does the nation owe a large debt of gratitude for the perseverance with which, through evil report and good report, amid endless discouragements and deep personal affliction, he has steadfastly and unswervingly labored for the humane object of mitigating some of the dreadful horrors of the battle-field by the organization of an improved system for ministering promptly to the necessities of the wounded. It is to the noble earnestness and zeal of our honored associate, more perhaps than to any other agency, that the public interest has at length become aroused, and the establishment of a uniform and efficient ambulance system, as it were, forced upon the action of Congress.

Nor should we overlook the valuable yet unobtrusive services rendered by others of our number as agents of those great national charities, the UnitedStates and Western Sanitary Commissions. 1 will not parade the names of the gentlemen of this So-

- Willia J. Dale, M.D. † Hengy I. Bowditch, M.D. 
ciety who have promptly responded to calls made by these organizations for professional services at a time when the machinery of the medical department of the army was as yet inadequate to its task; repairing at once to the scene of most urgent need, and cheerfully performing whatever work came first to hand. The good they accomplished is their sufficient reward.

In connection with the Sanitary Commission, it is our grateful task to record the lasting gratitude of the nation to its women for their untiring efforts in behalf of suffering humanity. The value of their example is above all estimate: but of the extent of their labors some approximation may be gathered from a recently published statement of the UnitedStates Sanitary Commission,- that the contributions of hospital-stores to this charity alone have amounted to no less than seven millions of dollars; and this in addition to large donations of money, and to immense contributions distributed through other public and private agencies. This was before the recent unexampled contributions from the great fairs held in all our large cities, which have already swelled the amount to several millions more than that stated.

One of the sad duties assigned to the orator of this occasion is to recall the labors and record the virtues of those of our number who have died during the past year.

Since our last meeting, thirty-eight members of this Society, some of them among the most distinguished in their generation, have finished their work on earth, and now rest from their labors. 
One, an ex-President and most distinguished officer of this Society, of which he had been for more than half a century a fellow, ever laboring earnestly and efficiently in furtherance of its interests and in support of its dignity, in turn an honored and learned instructor and fellow of our University, having filled with distinction many high public trusts, was suddenly taken in the full activity of a ripe but vigorous age.

Another, $\uparrow$ whose sudden death we also mourn, long a successful and beloved practitioner in a neighboring city, and having but yesterday, as it were, come among us, had already won the esteem and love of every one, by the display, in a rare degree, of those highest moral and intellectual qualities which characterize the wise and skilful physician and the true Christian patriot.

A third, $\ddagger$ an honorary member of this Society, a native of Boston, and a graduate of Harvard, for many years a resident of London, where he had gained high distinction as well for his professional skill as for his eminent scientific attainments, had endeared himself to thousands of his countrymen by his kindly manners and considerate attentions. Although resident abroad for ncarly fifty years, how many among us feel in his death the loss of a personal friend as well as of a most distinguished member of our profession!

- George Haywarn, M.D., late Professor of Surgery and Clinical Surgery in Harvard University, Presilent of the Massachusetts Medical Society, \&c., died Oct. $5,1863$.

† Johx C.a.l Dalton, M.D., died Jan. 8, 1864.

$\ddagger$ Francis Boott, M.D., Fellow of the Royal College of Physicians, VicePresident of the Linnæan Society, \&c., died Dec. 25, 1863. 
And, lastly, within the past month, yet another of our most honored associates," a late President of this Society, and for more than a quarter of a century Professor of the Theory and Practice of Medicine in our school, has been suddenly called to another and higher sphere of labor. Eminent as a teacher for the soundness of his reasoning and the judicious moderation of his views, his precepts have left a deep and enduring impression on the minds of a whole generation of followers. Distinguished in his professional relations for lofty integrity of purpose, eminent fairness in discussion, and modest confidence in the expression of his carefully matured opinions, he gained the affection and respect of his younger brethren by his uniform kindness of manner, and considerate regard for their interests.

In recalling the memories of our departed friends, we are insensibly led to consider a few of the causes which helped to raise them to the eminent social and professional stations they so worthily adorned; and, for an enumeration of the qualities most essential to success in the practice of the healing art, I know of no writings, which, for quaint appropriateness, compare with the ancient Hindu "Shastras," or sacred books of medicine. $\dagger$ The quaintness of the few extracts, with which I conclude, will be readily excused in view of their remarkable good sense and high moral tone.

- John WARe, M.D., late Hersey Professor of the Theory and Practice of Medicinc, President of the Massachusetts Medical Society, \&c., dicd April 29, 1864.

† See "Commentary on the Hindu System of Medicine." By T. A. WIrB, M.D. Calcutta : 1845. 
"The scholar, on beginning his lessons, must thenceforth discard lust, anger, covetousness, ignorance, laziness, vanity, pride, envy, revenge, cruelty, lying, and evil actions. He must always be engaged in the search after truth, and in the performance of good actions; he must be clean in his person, must harbor no bad thoughts, must be moderate in the indulgence of the appetites, and must be contented with a small recompense; he must avoid bad company, and avoid entering a house as a medical man without an invitation."

"He must study the "Shastras' with care; but if a physician does not know, or does not follow, the precepts of the 'Shastras,' he will be like a thief, and will commit as great a sin as beating a Brahman."

"The physician should possess a healthy body; he should keep his nails and beard short, his body pure, his clothes clean, and wear shoes and a small turban. He should carry an umbrella and stick in his hand." "He should study to remove curable diseases, but should avoid treating healthy persons."

"The physician must have practised his profession as well as have studied the "Shastras." "Without such a knowledge of books, he will be confused, will be a great sinner, and should be capitally punished by the rajah. On the other hand, a want of practical knowledge will impede his advancement, and his senses will be bewildered when called upon to treat acute diseases." "A physician, if he is to acquire celebrity, must still daily endeavor to improve his mind by an attentive perusal of scientific books. If such a physician does not gain money, it is his own fault." 
"A bad physician may cure one patient, by which he endeavors to establish his fame, without considering the thousands he has killed. Such a fellow is as a deadly serpent, and should be avoided."

The practical shrewdness displayed in the following precepts sufficiently commends them:-

"The physician should avoid visiting a sick person during the night." "If the physician visits the patient by night, the person will die of the disease."

"It is necessary to recollect that a good Brahman and a rajah will be cured of a disease with difficulty, as they will not always take the proper remedies, and the physician is afraid to urge his instructions strongly."

"A person rejecting a physician will be punished in hell ; whereas, when a physician is employed, the patient will go to heaven, even should he not be able to see the sacred Ganges in his dying moments."

\section{RECOMPENSE OF THE PHYSICIAN.}

"When a physician has cured a disease, he is entitled to the usual gift for the performance of a good action. These will vary with the rank and condition of the patient. Money will be the recompense bestowed by the rich ; friendship, reputation, increase of virtue, prayers, and gratitude, will be that of the poor. When a Brahman, a relative, an humble and good friend, or one without relations, consults a physician, he must not accept of any pecuniary recompense: his reward, in such cases, will be an increase of knowledge, and the gratification of his desires in having an opportunity of performing a good ac- 
tion. His cures will insure the admiration and the esteem of all men; he will be honored and respected as a master; and, after death, he will go to heaven. Should the patient prove ungrateful after being cured, his holiness and good fortune will pass to the physician. But the physician must avoid administering remedies to hunters or great sinners: such people do not deserve his assistance." 